\title{
O Comportamento do Consumidor de Informações
}

\author{
Raquel Dias \\ Instituto de Cooperação e Assistência Técnica da AEUDF - Av. W4 Sul - Q 704 - Brasília - DF \\ raquel_dias@directnet.com.br
}

\begin{abstract}
Resumo - O objetivo deste artigo é mostrar a semelhança do comportamento dos usuários de sistemas de informação e de consumidores de bens e serviços. A informação pode ser tratada como um produto de consumo porque está sob a influência dos fatores que estimulam demandas e promovem as mudanças no comportamento das pessoas, evidenciando preferências. Sob este enfoque, as instituições provedoras de informação deverão ser projetadas como lojas de departamentos com especial atenção à reincidência do negócio oriunda dos consumidores satisfeitos.

Palavras-chave: Gestão de Sistemas, Usabilidade, Utilização de Sistemas de Informação, Tecnologia da Informação.
\end{abstract}

\begin{abstract}
The objective of this article is to show to the similarity of the behavior of the users of information systems and consumers of goods and services. The information can be treated as a consumption product because it is under influence of factors that stimulate demands and promote the changes in the behavior of the peoples, evidencing preferences. Under this approach, the Institutions of information must be projected as department stores with special attention the relapse of the businesses deriving of the satisfied consumers.

Key-words: Management of Systems, Usability, Utilization of Information Systems, Information Technology
\end{abstract}

\section{Introdução}

A teoria do consumidor apresenta três conjuntos de agentes que atuam diretamente no processo de formação de demandas por bens e serviços. [1] , [2].

Tratando a informação como um bem de consumo, tais agentes poderiam ser descritos como:

$\square$ os consumidores, neste caso considerados como os usuários de sistemas de informação;

$\square$ os proprietários dos recursos que operacionalizam o processo produtivo, e às vezes até fornecem os insumos a serem utilizados na produção de qualquer conjunto de bens ou serviços, neste caso, representados pelos provedores de informações, que podem em algumas situações ser os próprios geradores (autores) da informação;

$\square$ as pessoas que se mantêm através da utilização e venda de recursos e/ou serviços produzidos por outros, aqui podendo ser consideradas como os prestadores de serviços e distribuidores da informação.

Aqueles que organizam de forma ótima os recursos e se antecipam aos desejos dos consumidores são recompensados com a renda que os mantêm no mercado, tanto na condição de consumidores como produtores e/ou provedores de bens e serviços e informações.
Todas as pessoas que ganham renda monetária pertencem ao conjunto dos agentes econômicos denominados consumidores. Cada consumidor tem noção dos bens e serviços que pretende consumir. É notório que além dos fatores orçamentários limitantes, existem outras razões, tais como os estímulos a consumir, que direcionam o comportamento do consumidor. No entanto, de qualquer forma, o esforço mais ou menos consciente em atingir a satisfação máxima, com um orçamento limitado, determina a demanda individual por bens e serviços. Cabe notar, que tal satisfação, nem sempre é material. Compram-se coisas supérfluas, contextualmente, desnecessárias apenas pelo prazer de possuí-las.

No caso dos usuários de sistemas de informação, a capacidade de pagar pela consulta ou pela informação, ou mesmo a disponibilidade de tempo para a busca, em casos de acesso gratuitos, constituem os fatores limitantes. A qualidade, facilidade e acessibilidade à informação, podem ser vistas como fatores estimuladores para a manutenção do usuário como cliente de determinado provedor de conhecimento.

\section{O Pleno Conhecimento das Necessidades}

Vamos considerar que cada indivíduo tenha informações completas sobre todos os problemas 
pertinentes a suas decisões de consumo. Isto significa dizer que o consumidor, além de conhecer suas necessidades, conhece ainda os custos e as potencialidades técnicas de todos os bens e serviços disponíveis no mercado, de forma que possa classificá-los como bens ou serviços capazes de satisfazerem suas necessidades. Esta é a base de conhecimento necessária para o delineamento das curvas de indiferença ${ }^{1}$. Em resumo, é necessário que o consumidor conheça, basicamente:

$\square$ o conjunto de bens que lhe interessa face às suas necessidades,

$\square$ sua reação de preferência em relação a eles e, finalmente,

$\square$ a disposição de algum recurso para oferecer em troca do bem, podendo ser tanto recursos pecuniários como, em muitas situações, disponibilidade de tempo, no caso do uso de sistemas de informações,

O pleno conhecimento de suas necessidades e a disponibilidade de recursos para a realização da troca permite que o consumidor possa transformar suas reações de preferências em ações, realizando aquisições dos bens ou utilizando-se de serviços, em busca da satisfação de suas necessidades ou do seu bem estar econômico.

A Teoria do Consumidor focaliza a utilidade e satisfação das pessoas, individual e/ou coletivamente, sob duas abordagens clássicas. A primeira baseia-se no princípio da utilidade marginal $^{2}$ mensurável, e porisso é conhecida por Teoria da Utilidade Cardinal. A segunda está centrada na análise da utilidade marginal discutida sob o aspecto da ordinalidade das preferências (as curvas de indiferença), e porisso conhecida como Método da Utilidade Ordinal.

\section{A Função Preferência}

As curvas de demanda do mercado têm origem no consumidor. Quando um consumidor adquire um bem ou faz uso de um serviço, ele obtém satisfação com a posse desse bem, que é percebida como a utilidade do bem. A utilidade total obtida de um bem atinge um nível de saturação, a certo nível de quantidade adquirida, e a partir daí começa a cair, por diversos fatores, como por exemplo, as dificuldades de armazenagem. Daí

\footnotetext{
${ }^{1}$ Curvas de indiferença: gráficos que demonstram as preferências e as indiferenças de um consumidor em relação a bens que deseja adquirir.

${ }^{2}$ Utilidade marginal: acréscimo de utilidade quando se adiciona mais uma unidade de um bem.
}

surge o conceito de utilidade marginal decrescente ${ }^{3}$. [1], [2].

Um indivíduo que obtém satisfação ou utilidade de cada bem ou serviço deve ter a capacidade de comparar diferentes situações restritivas ou custos, e determinar suas preferências dentre eles. Assim, a função preferência é determinada por um conjunto ordenado de preferências de acordo com as condições restritivas de recursos a serem trocados pelos bens.

A função preferência é caracterizada por duas relações: preferência e indiferença.

A expressão matemática da função preferência é :

$$
\varphi=\varphi(x i, x i+1, \ldots, x n) \text { para } i \text { variando de } 1 \mathrm{a}
$$

$\mathrm{n}$

onde: $\mathbf{x i}=$ quantidades da i-ésima mercadoria

$\boldsymbol{\varphi}=$ orçamento, ou total de recursos disponível para a obtenção da mercadoria.

Isto quer dizer que o consumidor deverá compor sua cesta de bens tendo como restrição sua disponibilidade financeira para comprá-los. A preferência está sendo expressa aqui pelas quantidades diferenciadas dos bens, consumindo-se mais de um bem em detrimento do consumo de outro. As quantidades dos bens expressam, de forma quantitativa, as preferências do consumidor.

No caso de consumo ou uso da informação pode-se adaptar a função preferência como a "n"

$$
\varphi=\varphi(x \mathrm{i}, \mathrm{xi}+1, \ldots, \mathrm{xn}) \text { para "i" variando de } 1
$$

onde:

xi: volume de informações úteis, obtidas por visita, o que pode ser interpretado como um acesso a determinado sistema de informações, ou mesmo uma consulta a um provedor de informações. Pode ser calculada através da razão entre o volume, (neste caso visto como quantidade de itens) de informações recuperadas e 0 volume de informações úteis. Este resultado pode ser considerado como um índice de utilidade da cobertura ${ }^{4}$.

$\boldsymbol{\varphi}$ :orçamento (custo), ou tempo despendido para a realização da consulta.

\section{Considerações sobre a Utilidade}

Sob a luz da teoria econômica, utilidade significa a qualidade que estimula o desejo de se obter um bem. Trata-se de um fenômeno subjetivo

\footnotetext{
${ }^{3}$ Utilidade marginal decrescente: medida que indica que o nível de utilidade de um bem cresce a taxas menores cada vez que se adquire mais unidades do mesmo

${ }^{4}$ Cobertura corresponde ao nível de abrangência do assunto pelo texto
} 
em função das diferentes formações e níveis de conhecimento e necessidades das pessoas.

Inicialmente, acreditava-se que existissem dois obstáculos básicos, para a modelagem do comportamento do consumidor: primeiro 0 conhecimento das dificuldades da mensuração da intensidade da satisfação do consumidor, aqui referenciada como utilidade. O segundo obstáculo seria a dependência da realização dos desejos face aos bens complementares necessários para a usabilidade de determinados bens. Assim, assumiase a utilidade como uma qualidade mensurável e aditiva. [1], [2].

Posteriormente, considerou-se que a teoria da utilidade não dependia da hipótese da aditividade, pressupondo que a utilidade é uma qualidade mensurável e geralmente não aditiva, não devendo ser observada para cada bem, mas de uma forma global, formando superfícies de utilidade relacionando o nível de utilidade às taxas de consumo de todos os bens. Este enfoque removeu a objeção de que as utilidades seriam dependentes e aditivas, porém deixou clara sua dependência com a quantificação da utilidade de forma cardinal.

A base para a remoção da segunda objeção foi fornecida por Pareto, que propiciou o estudo da teoria ordinal do consumidor .

Passa-se, assim, de uma teoria inicial da utilidade mensurável aditiva e da superfície de utilidade associada, ao conceito de preferência e indiferença. A principal distinção é a natureza da escala de medida envolvida. A contribuição de Pareto foi demonstrar que apenas a medida ordinal era suficiente. Ou seja, o principal requisito seria que as curvas de indiferença ordenassem as preferências dos consumidores em função de suas situações restritivas de recursos a serem utilizados na aquisição do bem.

As curvas de indiferença possuem características importantes para a teoria do comportamento do consumidor de bens, serviços e informações. A primeira atribuída à substitutibilidade dos bens no consumo. No caso de bens de informação pode-se traduzir esta primeira característica como a capacidade do consumidor em escolher qual provedor ou informação irá utilizar. Ou seja, as opções de escolha do consumidor. A segunda é uma necessidade e a última, e talvez a mais importante característica, é a disposição do consumidor em agir rumo a maximização da satisfação face ao seu poder de compra.

As curvas de indiferença são negativamente inclinadas (inclinam-se para baixo e para a direita) isto significa dizer que se a curva fosse horizontal ou vertical, o consumidor seria indiferente entre duas combinações, ou seja, estaria saturado de um dos bens, ao ser considerada cada curva. Estas curvas indicam o fato de que um bem pode ser substituído por outro de forma a manter o mesmo nível de satisfação.

São côncavas, ou convexas em relação à origem. Sob esta característica pode-se calcular a taxa marginal de substituição de um bem por outro, que pode ser definida como sendo a quantidade de um bem que o consumidor esta desejando ceder para obter uma unidade adicional de outro bem e manter o mesmo nível de satisfação. Se a taxa de substituição diminui, quando variamos para maiores quantidades de um bem, e a quantidade desse bem está descrita sobre o eixo das abscissas, então a curva de indiferença é convexa em relação à origem (isto é raro). Se ocorrer o contrário, a curva será côncava em relação à origem. No caso da taxa de substituição permanecer constante quando variamos de menores para maiores quantidades de um bem, a curva de indiferença será uma linha reta, indicando que os bens são substitutos perfeitos. As curvas de indiferença não se interceptam.

É importante ressaltar que um mapa de indiferença de um consumidor representa seus desejos, enquanto que a linha de orçamento representa os preços dos produtos e a renda do consumidor. O mesmo nível de utilidade se mantém ao longo de uma curva de indiferença. Se houver um deslocamento de um ponto com menor quantidade de um bem para outro com maior quantidade teremos deixar de desejar consumir quantidades de outro bem considerado, e , por conseguinte haverá perda da utilidade proporcionada por esse bem, que deverá ser compensado pelo incremento de utilidade ganho com o acréscimo de consumo do outro bem.

$O$ ponto de tangência entre a curva de indiferença e a linha de orçamento indica o mais alto grau de indiferença que um consumidor pode atingir, quando a curva for convexa em relação à origem. É uma posição de equilíbrio para o consumidor. As curvas côncavas são raras, e neste caso o ponto de tangência não indicará indiferença máxima.

\section{A Maximização da Satisfação}

A principal hipótese sobre a qual repousa a construção da teoria do comportamento do consumidor e da demanda é que o consumidor procura alocar seus recursos, para a realização da troca, limitados entre bens e serviços disponíveis de tal forma a maximizar sua satisfação.

Em resumo, o consumidor organiza suas aquisições de modo a maximizar sua satisfação que está sujeita a sua disponibilidade de recursos para a troca. Dada esta suposição e as propriedades 
das curvas de indiferença, as curvas de demanda individuais podem ser determinadas. [1], [2].

\section{A Curva de Demanda ${ }^{5}$}

A partir do mapa de indiferença ${ }^{6}$, dos preços dos produtos envolvidos e da renda, é possível deduzir uma curva de procura para um dos produtos.

Então, a curva de demanda de um consumidor individual por um determinado bem especifica e relaciona as quantidades de equilíbrio de um bem adquirido ao preço de mercado, mantendo-se constantes a quantidade de recursos disponíveis para a troca e os preços nominais das demais mercadorias.

A quantidade demandada varia inversamente com o preço, permanecendo constantes a renda e os preços dos demais bens (ceteris paribus ${ }^{7}$ ).

\section{A Elasticidade da Demanda}

A elasticidade da demanda é um conceito importante e corresponde à resposta relativa da quantidade demandada do bem em função das variações do preço. Pode também ser determinada pelas variações no preço e na renda monetária gasta em um bem.

Os princípios básicos do comportamento do consumidor e da demanda individual foram aqui apresentados. Se os consumidores individuais agem de forma a maximizar sua satisfação com uma renda monetária limitada, sua quantidade demandada variará inversamente com o preço

Até aqui, utilizamos as curvas de indiferença para a dedução de curvas de procura de indivíduos por produtos específicos. É importante notar que podemos utilizar as curvas de indiferenças para analisar o efeito de um determinado incentivo sobre um indivíduo, como uma política com prática de preços mais acessíveis, ou disponibilização de determinados serviços adicionais em um provedor de informação.

Após um estudo de satisfação de usuários, traçando os mapas de indiferenças poder-se-ia quantificar os investimentos e/ou os níveis de preços e melhorias nos serviços a serem praticados para deslocar a curva de indiferença do usuário para a direita e para cima. Para isto, basta traçar uma linha de orçamento paralela a anterior expressa na

\footnotetext{
${ }^{5}$ Curvas de demanda: gráficos que demonstram o comportamento do em relação à procura por bens.

6 Mapa de indiferença corresponde ao conjunto de curvas de indiferença relativa às preferências de um consumidor.

7 Ceteris paribus: condição de avaliação de uma variável considerando que as demais permaneçam constantes
}

curva de indiferença do usuário, tangente à curva de indiferença proposta.

\section{O Significado de Marketing}

A palavra marketing para os provedores de informação significa promoção, anúncio, venda de serviços e de informação. Para muitos outros significa exploração, persuasão, e tentativas de manipulação do consumidor induzindo-os a comprar bens e serviços dos quais ele não necessita. [3].

Smith identificou três fases distintas na orientação dos produtores e distribuidores de bens a consumidores. A primeira fase consiste na orientação do produtor ao controle de qualidade nos processos de produção e nos produtos. A segunda fase refere-se para a realização do esforço promocional forte o suficiente para encorajar consumidores a realizarem aquisições dos produtos e/ou serviços ofertados, lembrando sempre de que o melhor produto não vende por si só. A realização da venda depende muito mais da eficácia da campanha promocional do que do produto propriamente dito. Finalmente, a terceira fase conduz ao estudo do comportamento dos usuários. Os hábitos e as necessidades dos consumidores variam ao longo do tempo. Alguns compram mais freqüentemente do que outros, e uma pequena proporção de compradores geralmente são responsáveis pela proporção maior de vendas. Desta forma, percebe-se a necessidade de criação de perfis teóricos de consumidores e de estratégias de segmentação de mercado, de modo a fundamentar o desenvolvimento de uma política de marketing eficiente.

De forma análoga, aborda-se o processo de provisão de serviços de informação direcionado para os usuários potenciais e reincidentes. É de se esperar que a parcela dos usuários reincidentes seja responsável pela manutenção do nível de utilização dos sistemas de informação e , portanto, pode ser considerada como uma variável importante no processo de previsão de demandas futuras.

Os aspectos econômicos evidenciam, no mínimo, a existência de três fatores que apóiam a abordagem da previsão de demandas por serviços de informação, sob a ótica do comportamento do consumidor: a explosão da informação, a revolução tecnológica e a evolução dos custos de tais serviços.

\section{A Explosão da Informação}

Pesquisas de quinze anos atrás sobre o crescimento de coleções em bibliotecas nos Estados 
Unidos indicaram, uma tendência a dobrar em tamanho a cada vinte ou trinta anos, demonstrando naquela época média anual de incrementos na ordem de 80.000 volumes [4] Seibert demonstrou a existência de evidências de um crescimento rápido na taxa de aquisições que foi característico na década de 1960 e começou a declinar, a partir da década de 70. Em 1977, totalizaram-se 7,5 milhões de volumes. Em 1987, o número declinou para 6,73 milhões, apresentando uma redução de $6 \%$ [5], porém apesar do declínio o crescimento mantevese explosivo.

Este declínio foi devido à perda da capacidade de compra de livros e periódicos, em face de restrições impostas pela necessidade de redução de custos.

O declínio da capacidade para comprar, bem como o desenvolvimento tecnológico nos processos de armazenagem e disseminação de informação são importantes fatores que podem ser responsáveis pelas mudanças que se começa a perceber, nas características e escopo dos serviços oferecidos pelas bibliotecas. Neste contexto a predominância da impressão convencional começa a perder, a cada dia, seu controle monopolístico demonstrado, anteriormente, sobre recursos de informações.

Hoje a Informação é distribuída e vendida em um número crescente de diversos formatos eletrônicos, multimídias. Assim, ao mesmo tempo em que os principais provedores de conhecimento, que são as bibliotecas, sofrem pressões econômicas para conter ou mesmo reduzir seus custos operacionais, podem ser observadas demandas crescentes por melhores e, tecnologicamente, mais sofisticados, níveis de serviços.

\section{A Revolução Tecnológica}

Como mencionado anteriormente, o desenvolvimento tecnológico na armazenagem de informação tem proporcionado mudanças nas características e escopo dos serviços de informações, devendo-se ressaltar que ainda mais significante é a influência do uso das tecnologias de comunicação de dados, com redes locais integradas com redes de longo alcance, permitindo aos usuários de sistemas de informação o acesso a informações de bibliotecas e de sistemas de informações diversos, disponibilizados nos demais provedores de informação, eliminando-se as fronteiras, e desta forma, rompendo-se os limites de espaço e tempo. Tais facilidades criaram uma categoria de usuários que devem ser encarados como uma clientela especial, potencialmente invisível, e por serem conhecedores do poder obtido com o uso da tecnologia da informação, tornaram-se mais exigentes no que concerne ao pronto atendimento com informações de melhor qualidade. Isto exige dos profissionais da Ciência da Informação um conhecimento técnico de Informática mais aprofundado sobre as soluções tecnológicas que maiores facilidades podem trazer aos usuários, além da necessidade de conhecer os perfis de usuários para melhor atender as suas expectativas.

Por outro lado, surge a dificuldade de conter a expansão dos custos em tempos de dificuldades de patrocínio. As taxas de crescimentos dos custos dos livros e periódicos tendem a crescer, principalmente, considerando o valor agregado face à necessidade de infra-estrutura tecnológica, contra uma política de redução de custos operacionais globais dos provedores diante das dificuldades econômicas.

A associação do custo, de serviços e da informação ao usuário, em função do uso ou da realização de determinada transação em um sistema de informação, específico, induz o usuário a empreender uma análise de custo benefício relativa ao valor efetivo da informação obtida, com vistas ao conhecimento do retorno de seus investimentos pessoais de tempo e/ou recursos financeiros.

A continuar as dificuldades orçamentárias, é provável que a relação entre provedores de informação, principalmente, as bibliotecas públicas e clientes tendam mais a vendas do que a empréstimos.

Este cenário é propício a realizações de estudos de comportamento dos usuários, ativos e potenciais, operando em um ambiente, para compreensão das suas necessidades de informação, com vistas a maximizar o uso e minimizar os custos.

Neste contexto, um interesse na análise da comunidade e efetividade dos serviços de informação, em bibliotecas e/ou demais provedores de informação, cabe a realização de estudos de marketing [5] que assumem uma significância particular, principalmente, sobre o aspecto da pesquisa do comportamento do consumidor reincidente, no qual concentramos nossas atenções neste trabalho.

Focalizamos, então, as ações de comprar e vender que implicam em troca de recursos.

No mundo comercial, isto geralmente envolve uma troca monetária direta baseada em valores correntes e futuros. Em um mundo não comercial, as pessoas trocam seu tempo por alguma informação ou serviço oferecido pelo provedor de informação, os quais elas consideram que possuem valores equivalentes. Este conceito de trocas 
considera um significado de natureza esclarecedora relativo ao relacionamento entre provedor de sistemas de informação e seus usuários ativos e/ou potenciais.

A desagregação dos dois tipos de usuários (ativos e potenciais), deve ser vista com reservas, considerando o risco que se pode incorrer em levar à provisão de serviços e produtos muito sofisticados e caros que não sejam relevantes para as necessidades dos usuários. Por outro lado, alternativamente, poder-se-ia desenvolver um cenário no qual a demanda dos provedores, se não for prevista e planejada com precisão, possa não gerar respostas satisfatórias em termos de custos e qualidade, resultando numa deterioração nos serviços, e conseqüentemente, em clientes insatisfeitos.

Além disso, no campo da provisão da informação, cabe a observação do elemento de escolha e as leis de oferta e procura, que neste momento, base para nosso trabalho, já que estamos tratando a informação como um bem de consumo e como tal sujeita às leis de mercado.

\section{O Modelo de Uso em Bibliotecas e demais Provedores de Informação}

Duas observações podem ser feitas sobre o uso de bibliotecas e/ou demais provedores de informações. Em primeiro lugar, é importante ressaltar que a maioria do que conhecemos é sobre usos e não sobre usuários. Em segundo lugar, pelo que se pode depreender dos estudos já realizados anteriormente, parece que existe uma tendência em basear estudos de usuários sobre questionários e conjuntos de opiniões. A questão de como usuários realmente se comportam, em oposição ao que eles dizem ou pensam sobre comportamentos, não parece que tem recebido a atenção merecida.

Com relação ao padrão de uso de biblioteca e demais provedores de informação, e com base dos estudos publicados pela literatura, sugerimos alguns aspectos a serem considerados, quando tratarmos de escolha de modelos para obtenção de métricas de performance, conforme segue.

$\square$ Uma das principais dificuldades com os dois instrumentos mais usados, para conduzir estudos de usuário é que ambos, questionários e entrevistas dependem mais dos dados inferidos do que dos obtidos sobre a coleção de exemplos reais. [6]

$\square$ Estudos sobre comportamentos relacionados com o uso de biblioteca têm apresentado taxas de erro em torno de $13 \%$ considerando que a questão básica perguntada tenha sido, simplesmente, se o respondente possui ou não um cartão de acesso à biblioteca [7]. Desta forma, seria prematuro antecipar que uma percentagem mais alta de erros corresponderia à norma, quando forem feitas questões mais sensitivas, envolvendo mais detalhes sobre fatos ocorridos durante um período de tempo determinado.

$\square$ Fine observou um deslocamento no foco das pesquisas comportamentais em biblioteca para uma perspectiva de consumidor mais intensiva. Ainda assim, permaneceu uma lacuna de informações sobre como os usuários, atualmente, se comportam quando providos com opções de escolha de usar ou não a biblioteca.[8].

$\square$ Apesar da atividade de grupos que mantêm um relacionamento não usual com biblioteca, tais como visitas de crianças, programas de educação de adultos, grupos especiais de interesse, o usuário de serviços de bibliotecas é visto mais como um indivíduo do que, propriamente, como um membro de um grupo.

Ainda sobre o aspecto de mensuração de serviços de biblioteca (saídas), serviços orientados individualmente (circulação de materiais considerada tanto interna quanto externamente à biblioteca, referências e questões direcionadas, facilidades usadas ou espaço consumido) são relatados como base dos estudos, não considerados sobre a quantidade de indivíduos usando tais serviços, mas sobre o total de das interações com a biblioteca, restringindo os relatórios à contagem de transações, medindo desta forma livros e não usuários emprestadores. [9] Um dos fenômenos de uso de biblioteca, que é familiar para qualquer bibliotecário, com experiência em trabalhos com circulação ou referência, é a forma pela qual o uso está distribuído e o grau de variação entre indivíduos.

No desenvolvimento desta teoria Twedt observou que, para muitos produtos no mercado, notou-se que cerca de $50 \%$ dos consumidores eram responsáveis por $80 \%$ do consumo. Similarmente, para muitas bibliotecas e/ou provedores de informação, o usuário gera incrementos nas atividades, mas acrescenta uma pequena proporção quando observamos os usuários reais atendidos. [10]

Isto, obviamente, nos leva a acreditar que alguns usuários tendem a usar a biblioteca muito mais freqüente e intensamente do que outros, demonstrando níveis de utilização diferenciados, mesmo quando se observa o mesmo usuário em provedores de sistemas de informação e/ou bibliotecas variadas.

A base principal de nosso estudo é a observação da informação como um bem de 
consumo e em conseqüência, a mensuração da importância da presença freqüente do usuário nos provedores de informações, como um comprador reincidente, sobre os quais regem as leis de marketing e a teoria do consumidor. Como poderemos definir o uso reincidente e como isto funciona em uma biblioteca? Estas premissas e observações serão utilizadas na elaboração do modelo para avaliação e previsão de utilização de sistemas de informação, com o intuito de prever demandas para melhor alocar recursos para o atendimento ao usuário de tais serviços.

Primeiramente, vamos considerar os usuários de bibliotecas e/ou de demais provedores de sistemas de informação como consumidores. É importante relatar os resultados de estudos já realizados sobre o comportamento desses usuários, utilizando os modelos matemáticos, aplicados por Ehrenberg para estudar o comportamento de compradores repetitivos de produtos adquiridos no mercado. A observação sob esse aspecto transferindo a aplicação destes modelos para um conjunto de bibliotecas ou de demais provedores de informação, certamente demonstrará o relacionamento entre 0 comportamento dos consumidores de um modo geral com os freqüentadores de bibliotecas e provedores de informação.

O argumento para o uso de modelos matemáticos em pesquisa comportamental para o propósito de relacionar usuário e provedor, entre passado, presente e futuro, e entre o conhecido e o desconhecido foi introduzido por Greene: "certamente, modelos de mercado são maneiras para conhecer a historia de mercado e não estamos condenados a repeti-los para sempre, tampouco as mesmas velhas pesquisas pelas quais os registramos." [11] Trueswell, formulou uma adaptação da lei de Pareto, na qual ele propôs uma regra de 80/20: $80 \%$ da circulação das bibliotecas concentra-se em $20 \%$ de seus pertences. [12]

Line sugeriu uma técnica para determinar a taxa de declínio no uso de periódicos baseado na determinação de sua meia vida, delineando uma analogia para ciências físicas relacionadas com a decadência de substancias radioativas. [13]

Finalmente, McGrath apresentou uma correlação entre a circulação externa e o uso em bibliotecas como dois fatores no modelo global de usos de material de biblioteca, que seria capaz de substanciar assunções prévias de que a circulação registra uma tendência e daí mostrar o modelo global de uso de biblioteca [14].

Apesar desses esforços observa-se que não houve crescimento do grau de interesse no conhecimento prévio do comportamento dos usuários quando tratamos de material de bibliotecas. Pode-se atribuir tal fato às dificuldades para fazer generalizações úteis sobre tais usuários, considerando que na maioria dos casos existe a forte presença de variáveis subjetivas que provocam vieses nas generalizações.

Poole, através de seu livro Theories of the Middle Range, apresentou uma clara e concisa revisão da história e desenvolvimento de estudos de uso de bibliotecas a partir do estudo mais antigo que identificou, ocorrido antes dos anos 70. [15]

A razão para cada interesse, a longo termo, no uso de informações tem sido tomada como uma necessidade para direcionar a política de informação nas instituições de um modo geral. [16]

Algumas das razões apresentadas para a baixa quantidade de estudos podem ser:

$\square \quad O$ descrédito dos achados de estudos anteriores.

$\square$ A convicção de que cada disciplina, instituição provedora de serviços de informação é tão única nos seus requisitos de processamento de informação e comportamento, que somente um novo estudo poderia ser suficiente para direcionar suas políticas de informação [16]

Em 1968, mais de 1000 estudos sobre necessidades e usos além de revisões, montaram um considerável corpo de literatura de pesquisa. [15]

Poole concluiu que para a maior parte destes estudos as características mais comuns foram as disparidades de resultados, a falta de síntese, e a validade questionável. [15] Daí a menção do termo "descrédito" como uma das razões para a baixa quantidade de novos estudos sobre o comportamento do usuário.

O resultado, então, foi que, apesar de uma multiplicidade de estudos de usuários, mantém-se a falta de uma clara e racional observação do comportamento de usuários de bibliotecas e demais provedores de informação. Com relação a este resultado, Fine apresentou uma declaração bem concisa do problema:

Para cumprir sua missão, bibliotecários precisam estar embasados na compreensão teórica, bem fundamentada, sobre a natureza da informação, a natureza e necessidades dos seres humanos, o processo de transferência entre pessoas e fontes de informação e a maneira com que as pessoas usam a informação. [8]

Percebe-se, diante disto, que há uma necessidade premente de que bibliotecários, produtores e provedores de informações tenham compromissos claros com as dimensões comportamentais fundamentais dos usuários, através de um corpo cumulativo de pesquisa comportamental [8] 
Greene considerou a dicotomia potencial que existe entre os aspectos teóricos e práticos da pesquisa comportamental.

Assim, observa-se que freqüentemente os modelos factuais são grandes, complexos construídos sobre homens ou grupos de opiniões, elaborados sem considerar padrões discernidos em dados passados, não verificados e até não verificáveis, propiciando informações enviesadas sem utilidade para o futuro, refletindo-se sobremaneira, tal futilidade, na proliferação de dados não modelados para suas próprias causas [11]

Observa-se, ainda, que no passado estes detalhes talvez não tenham sido alvo de atenção, considerando como resultado o significativo número de estudos de uso de bibliotecas e usuários, conduzidos ao vazio sem base teórica ou relacionamento com os achados em outras pesquisas.

Nozik apresentou alguns exemplos de pesquisas conduzidas sobre este tópico: uso de regressão múltiplas, para predizer nível de uso de bibliotecas [17], uso de uma distribuição de probabilidades geométrica para predizer o numero de tarefas, [18] desenvolvimento de modelos tipo Poisson para predizer demandas por serviço de informação para médicos [19] um modelo exponencial para estimar demandas futuras para concepção de serviços correntes, e um modelo de simulação de usuários de bibliotecas para predizer demandas por materiais monográficos [20]. Depois de revisar cada um destes modelos, Nozik vislumbrou as seguintes conclusões:

$\square$ com exceção do modelo de regressão múltipla, nenhuma destas técnicas tem sido usada, freqüentemente, em situações de bibliotecas.

$\square$ É difícil dizer se, de fato, algum outro usuário além dos pesquisadores tenha usado os modelos. Fontes de literatura não têm demonstrado tais evidências. [20].

O que antecipamos como premissa básica deste presente estudo, provê a simulação para um estudo mais intensivo do fenômeno do uso repetitivo, como uma fonte de informação sobre o padrão de uso de bibliotecas, e/ou provedores de sistemas de informação, e seus potenciais efeitos sobre o planejamento e liberação de serviços de biblioteca, além de redução de custos.

A impressão geral que se tem, a partir desta breve revisão de estudos de usuários, é que há uma série de interessantes esforços em construção de modelos e ajuste de dados, com pequena atenção para detalhes ou relacionamentos de todas as variáveis como um conjunto global.

Mesmo que um elegante modelo matemático possa ser demonstrado, propiciando números certos sob condições de testes, que confiança podemos ter em suas aplicações no futuro e em outros contexto, se não formos capazes de prover alguma explicação racional do como, para quê, e porque ele se permite ser aplicável?

Paisley ressaltou que a resposta para este problema demonstra uma forte lacuna para o desenvolvimento de teoria, " a teoria teria o poder para explicar o básico, ressaltando princípios centrados no uso da informação." [16]

Sobre esta questão, Poole chamou a atenção para o conceito de "faixa média" desenvolvido por Robert Merton, onde define as características necessárias que um modelo deve ter como: [15]

$\square$ deve ser usado para direcionar questionamentos empíricos.

$\square$ Deve estar intermediado entre teoria geral, que são extraídas do fenômeno observado para prover uma acurada explanação deles, e as detalhadas e ordenadas descrições particulares que não são generalizadas no todo' [21]

$\square$ Deve usar abstrações que sejam similares para os dados observados e proposições que possam ser testadas empiricamente.

$\square$ Deve ter como objetivos delimitados aspectos de fenômenos, de forma a direcionar seu uso no desenvolvimento de teorias especiais.

- Não deve fazer, e sim logicamente derivar [21].

$\square$ Deve consolidar achados empíricos.

$\square$ Deve ser desenvolvido efetivamente, somente depois de uma "grande massa de informações básicas ter sido acumulada" [21]

O conceito de faixa média foi utilizado por Poole para obter resultados em observação dos estudos de uso da informação com vistas a determinar como eles estão relacionados, onde convergem conceitualmente, e quais os princípios ressaltados sobre o uso da informação que estão inseridos neles. [15]

Baseado na análises de 599 estudos de uso constantes da revisão anual de ciência da informação e tecnologia entre 1966 e 1981, ele isolou 48 conceitos e 95 proposições relativas ao uso de biblioteca e serviços de informação dos quais derivam três teorias de faixa media: [15]

$\checkmark$ usuários de informação esforçam-se para minimizar seus esforços;

$\square$ eles se esforçam para reduzir o risco de dor ou desconforto para si próprios;

$\square$ por gastar menos esforço, buscam evitar sofrimento.

Oldman ressaltou o fato de que os princípios de esforço mínimo é o único conceito que pode ser empregado por muitas situações de comportamento, mas prossegue esta observação, a qual utilizamos como base para este estudo, de que tendo a informação assumido o papel de bem de consumo, 
- Marketing e a Ciência da Informação podem serem vistos como complementos um do outro [22].

Faz sentido realmente começar uma abordagem para investigação de usuários de biblioteca e demais provedores de informação, centrada nos seus conceitos comportamentais, voltando-se para marketing e estudos de consumidor, mais do que a possibilidade de oferecer uma forma de confusão de contradições e incertezas que caracterizam, em geral, as pesquisas sobre comportamento de usuários de bibliotecas.

$\mathrm{Na}$ busca para aplicar o dito de Ehrenberg "de fatos para teoria, e retorno aos fatos novamente" algumas considerações de Menzel pareceram, particularmente, relevantes no presente contexto: [23]

É importante fazer uso das vantagens de relevantes e substantivas teorias tanto quanto de métodos de pesquisas e técnicas que estão disponíveis, primariamente, nas pesquisas de comportamento e outros ramos da sociologia e psicologia, e também nas análises de sistemas, marketing, pesquisas operacionais, engenharia industrial, e disciplinas correlatas. [24].

Além destes acrescentam-se as técnicas de análises de comunidade ou, como eles são normalmente, e conhecidos "analises de mercado e pesquisa de audiência” [25].

Foi sobre este contexto teórico que repousamos e conduzimos o presente estudo.

\section{O Consumidor e Demais Modelos de Comportamentos}

Antes de tentar explicar o comportamento e o processo de decisão dos consumidores individuais, é preciso conhecer e entender o comportamento do público alvo, o que deve ser explicado de uma forma global.

O comportamento do consumidor tende a variar com o tempo, então se torna praticamente impossível estabelecer com $100 \%$ de certeza que o comportamento de determinada pessoa quantificado em unidades de uma determinada atividade demonstrará uniformidade se for comparado em quaisquer dois pontos da curva ao longo do tempo.

Desta forma, se observarmos uma amostra de pessoas, tomada sobre um curto período de tempo é provável que encontremos um certo número de pessoas que estarão se comportando de forma atípica, quando comparado com seus padrões de comportamento a médio ou longo prazo. Por outro lado, considerando a capacidade do ser humano de reagir sob estímulo, é possível que exista alguma tendência que possa ser definida como um modelo padrão ou medida de comportamento que seja constante sobre períodos maiores de tempo. [26]

Sob a ótica do consumidor, a variável implícita que deve ser procurada é a taxa pessoal que caracteriza o hábito de comprar de uma população, sobre o qual estamos focalizando os estudos. Esta taxa de compra não pode ser observada diretamente, mas pode ser estimada pela média das freqüências de compras observadas (isto é , $0,1,2,3, \ldots \mathrm{n}$ vezes por semana) sobre determinado período de tempo para chegar a uma taxa de compra semanal característica. Esta taxa pode demonstrar variações com o passar do tempo, mas somente como uma conseqüência de uma mudança no padrão de comportamento do consumidor.

Para cumprir com o objetivo de modelar o padrão de comportamento que varia com o tempo, faz-se necessário estabelecer dois pressupostos básicos, sendo que cada um deve ser dividida em duas partes: [26]

$\square$ Cada pessoa tem uma predisposição ou variável latente (ex: taxa ou freqüência de compras) que tem um valor fixado sobre um determinado período de tempo.

$\square$ Diferentes pessoas possuem diferentes valores de variáveis latentes, mas a distribuição destes valores pelo número de pessoas pode ser descrita por uma função matemática específica.

$\square$ Para qualquer pessoa, com um determinado valor de uma variável latente, existe uma certa probabilidade de que seja classificada dentro de cada uma das categorias ou classes definidas pela pesquisa.

$\square$ A distribuição de probabilidade das classes da pesquisa, para assuntos com dados valores da variável latente, é também descrita por alguma função matemática específica.

É importante notar que existe uma classe de problemas estatísticos relacionados com eventos para os quais existem duas, e somente duas possíveis saídas, como, por exemplo, comprar ou não comprar, emprestar ou não emprestar, usar ou não usar. Não existe padrão fixo para estas conseqüências e a probabilidade que uma das duas ocorrerá é, logicamente, fixa e não demonstra variação de ensaio para ensaio.

Os processos que são distinguidos por estas características são conhecidos como processos de Bernoulli. A probabilidade que expressa a possibilidade de obter um número especificado de uma determinada decisão em um dado número de ensaios de Bernoulli é denominada de probabilidade binomial.

Alternativamente, existem casos nos quais precisamos conhecer a possibilidade inversa de um caso binomial. Por exemplo, poderíamos precisar 
conhecer a probabilidade que um ensaio de Bernoulli específico exija para obtenção de um determinado número de resultados, tal como a decisão de se fazer compras ou empréstimo de livros. Uma probabilidade deste tipo é denominada por distribuição binomial negativa. $O$ conceito formal de uma distribuição binomial negativa é uma distribuição na qual as freqüências relativas (probabilidades) podem ser obtidas por uma binomial com um índice negativo" [27]".

A distribuição binomial negativa tem sido estudada extensivamente, e tem sido útil para ajustes de dados observados em várias situações em muitos campos do conhecimento.

Em um dos mais poderosos modelos usados para analisar e predizer o comportamento do consumidor, a distribuição das taxas de compras características entre uma amostra da população é descrito por uma distribuição Gama, uma distribuição estatística de probabilidade para valores não negativos.

E importante relatar que a probabilidade de que um indivíduo, com uma dada taxa latente, agirá $0,1,2,3$, ou $n$ vezes em um determinado período de tempo é descrita pela distribuição de Poisson, que é um caso especial da distribuição binomial.

A combinação das distribuições Gamma e Poisson permitiu a composição de um modelo que pode ser utilizado para diferentes distribuições de freqüências de indivíduos que apresentem taxas diferenciadas para atividades diversas.

O modelo Gamma e Poisson foi originalmente imaginado para investigar taxas que explicariam a propensão a acidentes e doenças observadas em diferentes pessoas [26] Também já foi utilizada para analisar e explicar consumo de alimentos e bebidas, [11], bem como aquisição de gasolina . [23].

A aplicação da distribuição Gamma-Poisson, sob o título de Distribuição Binomial Negativa ou DBN na pesquisa de consumidor foi pioneiramente estudada por Ehrenberg, Chafield e Goodhardt. O modelo foi validado pelos estudos citados por Ehrenberg. e foi aplicado em estudos de padrão de compras repetitivas, [23] , [28]

Revisando os componentes do modelo DBN, considerando-se que um indivíduo específico, ou grupo social, ou família executam uma atividade especifica com freqüências variadas em sucessivos períodos de tempo iguais em tamanho, o modelo assume que estas sucessivas freqüências devem se comportar como amostras randômicas independentes de um sistema onde o evento possua a mesma probabilidade em qualquer ponto, no período de tempo dado, e onde as probabilidades sejam independentes. Esta é a distribuição de Poisson, que proporciona a parte estocástica do modelo que admite que as pessoas não fazem, em qualquer período de tempo específico, o que elas tendem a fazer em média, em longo prazo.

A segunda parte do modelo é centrada nas diferenças encontradas nas taxas em que os indivíduos executam a atividade específica. modelo pressupõe que a distribuição de freqüência de uma taxa média de diferentes indivíduos deve ser proporcional a uma distribuição Gamma.

Estas duas componentes do modelo são combinadas para produzir dois parâmetros da distribuição discreta para as probabilidades, "Pr", de quaisquer observações de inteiros não negativos, "r", sendo a taxa na qual a atividade especificada é executada. Os parâmetros do modelo são usualmente expressos como o significado, "m “" (a taxa de atividade média dividida pela taxa de individual). E o parâmetro Gamma , "k”, com a expressão "a $=\mathbf{m} / \mathbf{k}$ " sendo a função destes dois parâmetros.

As probabilidades, "Pr", surgem expandindo uma expressão da forma binomial com a expoente negativa ( $-\mathrm{k})$

$$
\frac{(1-m)^{-k}}{m+k} \quad \text { ou } \quad \frac{(1-a)^{-k}}{1+a}
$$

A principal justificativa para este modelo é que, na prática, ele ajusta muitos aspectos diferentes do comportamento do consumidor sob um grande intervalo de condições, isto é, a distribuição de compras em qualquer período de tempo único, a freqüência de compras repetitivas de um período para o próximo, e a maneira na qual os valores da penetração da população e freqüência média de compras variam em períodos de tamanhos diferentes.

A extensão para a qual as deduções do modelo tem sido encontrada para ajustar os fatos observados determina sua validade e utilidade prática.

\section{A Teoria do Uso Reincidente}

Muitos aspectos do comportamento de usuários ou consumidores podem ser previstos simplesmente através da média da freqüência de aquisições do item, e estas duas variáveis são interrelacionadas.

"Comprar repetidamente é qualquer situação onde uma pessoa compra o item em questão mais de uma vez. É o caso de uma pessoa que compra qualquer item específico mais de uma vez em um curto período de tempo, tal como uma semana, um mês, ou um ano, a noção de repetitividade, torna-se particularmente relevante." [23]

A continuidade de consumo, uso, ou venda de muitos bens e serviços dependem da satisfação 
dos consumidores, clientes ou pacientes sobre uma ocasião, e retornam dentro de um período de tempo subseqüente. Para sustentar a demanda, é necessário ter uma alta taxa de uso repetitivo.

É importante ressaltar que, mesmo que o número total de usuários seja alto, são os usuários reincidentes que podem sustentar o nível de demanda para um bem ou serviço depois que o conjunto de possíveis usuários em potenciais tenha se esgotado. [20]

A análise e explicação de fatores psicológicos, sociais e econômicos que influenciam o comportamento do consumidor é substancial. Nicosia enfatizou o processo de decisão do consumidor como uma oposição ao ato de comprar [29] Este processo é percebido como contínuo, isto é, precede e segue o ato de comprar; a ligação entre o primeiro e o subseqüente atos de compra é , entretanto inerente ao processo, e o fenômeno de comprar, repetidamente, torna-se inteligível em termos de ausência de fatores que possam descontinuar o padrão de decisão adotado, anteriormente. Howard e Sheth tentaram identificar os conceitos mais importantes que afetam 0 comportamento do comprador, tal como atitude, motivação, preço qualidade e satisfação, e a ligação deles e o impacto dos efeitos. [28]

Engel, Blackwell e Kollat formularam um modelo do comportamento do consumidor que tem similaridades com o de Howard-sheth, mas inclui as considerações das dissonâncias das pós aquisições e mudanças de atitudes [11]. Finalmente, Fishbein atentou para a importância das variáveis normativa e atitudinal no seu modelo de intenção comportamental. [28]

Ainda, apesar do número e complexidade de variáveis que se esperam que sejam preponderantes a influenciar o comportamento dos consumidores (isto é, atitudes, percepções, crenças normativas, preços anúncios, distribuição, etc.), a investigação sistemática do comportamento do consumidor tem demonstrado que pode existir um mesmo padrão empírico assegurado para um larga variedade de bens, produtos e marcas. É possível que exista alguma tendência simplista no trabalho na seleção de marca e fenômenos de compras repetitivas que constituam um nexo entre as necessidades que são identificadas e formuladas pelos consumidores e a informação com a qual eles são assediados por propagandas e outros persuasores ocultos.

Não é propósito deste estudo discursar sobre as origens e causas, nos termos psicológicos, desta tendência para adaptar certos modelos padrões de comportamento que podem ser empiricamente verificados, mas contribuir para melhorar o nível de entendimento de como as pessoas agem, e como pode ser esperado que ajam no futuro dado um mecanismo aceitável de predição.

Usando o DBN e sua aproximação simplificada, a distribuição de séries logarítmicas, Ehrenberg mostrou que os vários índices de compras repetitivas seguem padrões regulares cuja generalização abrange um largo espectro de marcas, produtos, períodos de tempo e outras condições. Os valores numéricos na questão oscilam com a freqüência média de compra por comprador. [23]

Os dados observados por Ehrenberg , apresentam as seguintes conclusões:

$\square$ Quanto maior a freqüência média de aquisições por comprador, maior a percentagem de vendas computadas para compradores repetitivos, isto é, quando alguém incrementa, então influencia o outro, embora não em uma maneira estritamente linear.

$\square$ A percentagem de vendas totalizadas para compradores que fazem pelo menos duas aquisições é diretamente relacionada com 0 número médio de aquisições por comprador. Novamente, quando alguém cresce, então influencia o outro.

$\square$ A percentagem de vendas contabilizadas por compradores é de pelo menos duas aquisições e a contabilização observada por compradores repetitivos são numericamente quase idênticas, com um coeficiente de correlação de 0,97.

$\square$ A taxa de compras de novos compradores tende a ser maior ou menos constante, com uma média de 1,5 e um desvio padrão de 0,2; em outras palavras, existe uma probabilidade maior do que $95 \%$ de que a taxa observada esteja entre 1,1 e 1,9 .

Ehrenberg demonstrou como, usando somente a taxa média de aquisições e a percentagem das populações que compram, na maioria dos casos o DBN proporcionará um bom ajuste teórico para dados observados de compras realizadas pelos consumidores,

$\square \quad$ Convém observar que o modelo de Ehrenberg é somente aplicável para um ambiente estável.

Por extensão pode-se considerar que a competição em um mercado é largamente objetivada em se:

$\square$ desestabilizando o ambiente para estabelecer um mercado para novos produtos, ou

$\square$ provocando uma mudança no padrão de consumidores para redistribuir o compartilhamento de mercado de produtos estabelecidos; a pressuposição de um ambiente estável não proporciona uma base prática para a predição de tendências futuras. 
O mercado de informação através de bibliotecas e demais provedores de serviços de informação é assunto que apresenta perturbações similares, embora com intenção diferente. Por exemplo, alguns fatores que podem intervir para interromper padrões de uso existentes são a realocação de recursos de bibliotecas e/ou demais provedores de informação, ou a substituição de uma estrutura permanente para uma estrutura móvel. Um incremento ou redução nas horas de serviços, maior precisão nos objetivos de forma a direcionar coleções e serviços para grupos específicos de usuários (ex.: idosos, pré-escolares, minorias étnicas); ou competição comercial vigorosa, por lucro, oferta de informação setorizadas como, por exemplo, para os setores industrial e comercial.

Nestes termos, o valor preditivo de qualquer modelo deve estar aberto para questões. De fato, pode ser levantada a questão de que existe pequeno escopo para a aplicação de um modelo preditivo que assuma a continuação de "status quo", e neste caso, o que existe para predizer que já não seja conhecido? Em sua revisão Ehrenberg proporciona as seguintes justificativas [26]

$\square$ O modelo é extraordinariamente parcimonioso. A estrutura completa do comportamento do consumidor para uma dada marca, ao longo do tempo, pode ser prevista a partir de dois fatos conhecidos deste comportamento.

$\checkmark$ Conhecendo somente o número de compradores em um período de tempo e sua freqüência média de aquisições, podemos realizar a predição utilizando o modelo para:

$\square$ a distribuição de freqüência completa no período de tempo, isto é, como muitas pessoas compram uma, duas ou mais vezes:

$\square$ a distribuição de freqüência completa em um momento subseqüente, ou precedente, considerando-se um período de tempo de mesmo tamanho ou de tamanho diferente;

$\square$ a comparação completa da distribuição de freqüência de determinada marca por dois ou mais períodos de tempo de tamanhos iguais ou diferentes, possibilitando a demonstração de como muitos consumidores compram uma ou duas vezes no período I, e também uma ou duas vezes no período II;

$\square$ a demonstração de como muitos consumidores compram em dois períodos (compradores reincidentes), considerando somente no segundo período, mas não no primeiro (compradores novos), no primeiro período, mas não no segundo (compradores infreqüentes), e etc;

$\square$ a média de freqüência de aquisições realizadas por consumidores novos, repetitivos, e infreqüentes, demonstrada separadamente. a distribuição de freqüência completa de aquisições, isto é, como muitas aquisições são contabilizadas por pessoa que compra uma ou duas vezes.

$\square$ O modelo pode ser mais útil quando usado para medir a variância entre duas de suas previsões e eventos reais que são previstos. Considerando que o modelo proporciona previsões normativas, isto é, eventos que acontecerão se nada foi mudado, poderá ser utilizado para decisão ou como um indicador de sucesso de um Programa de Governo para encorajar mais pessoas a praticar algum dos procedimentos simples, ou mesmo nas análises relacionadas ao crescimento de demanda, lançamento de uma marca ou manutenção de um produto ou serviço que esteja atraindo uma grande clientela, ou a interpretação de taxas de crescimento nas vendas de um produto qualquer.

Se um incremento é observado, será importante analisá-lo para determinar se corresponde ou não ao resultado do estabelecimento de uma base ampla de mercado, indicado por uma proporção de novos usuários em exceção à norma.

Por outro lado, um exame do modelo real de consumidores pode revelar que o crescimento das vendas é atribuível a aquisições mais freqüentes por consumidores antigos reincidentes estimulados por campanha publicitária .

O modelo possibilita comparações entre conjuntos de dados para verificação se estão realmente evidenciando as mesmas coisas ou se indicam diferentes visões.

Para se implementar mudanças, é necessário inicialmente 0 entendimento de uma situação estacionária, sem tendências, para que se possa, então, avaliar os efeitos das mudanças introduzidas, e seja possível realizar comparações dos resultados reais com o que poderia ter acontecido na ausência de tais mudanças. Desta forma, o fato do modelo não ser dinâmico afigura-se como uma vantagem.

Ehrenberg foi capaz de demonstrar que o DBN permanece válido para uma variedade de condições de mercado envolvendo vários subgrupos demográficos e percentagens de compradores, produtos, marcas, países, estações do ano e períodos de tempo. [28]

Se o modelo de compradores reincidentes pode ser aplicável também para o comportamento de usuários de bibliotecas e/ou de demais provedores de informação, sua utilidade geral como um dispositivo preditivo pode ser prontamente apreciado. Por exemplo, uma questão de alguma importância que é freqüentemente perguntada, mas 
raramente respondida com alguma medida de confiança é :

Qual é a representatividade dos usuários potenciais que fazem uso da biblioteca ou de determinado provedor de informação?

Como pode ser observado, basear uma resposta sobre resultados de uma pesquisa utilizando-se questionários não satisfará, plenamente, a questão. As respostas dos questionários tenderão a ser realizadas de acordo com o que os respondentes considerem ser a resposta certa esperada. Ou eles podem, inconscientemente, conduzir suas respostas interpretando a questão para o significado: Você já usou a biblioteca? Em ambos os casos os resultados, provavelmente, delinearão uma figura artificialmente inflada. Deste modo, ao invés de rever e ajustar esta figura por estudos através de amostras randômicas de respostas para determinar taxas de erros, seria mais simples obter uma estimativa sobre uma base confiável de dados relativos ao padrão real do comportamento dos usuários.

A pressuposição de que existem padrões simples e altamente generalizáveis é a premissa fundamental no estudo do comportamento.

Sobre a base da discussão precedente e as evidências adicionadas com respeito a necessidade de conhecer os padrões de comportamento de consumidor, foram propostas as seguintes hipóteses de investigação deste trabalho.

\section{Conclusões}

As Instituições provedoras de informações podem ser concebidas e projetadas como lojas de departamentos, com muita preocupação para reincidência do negócio oriunda dos consumidores satisfeitos.

Empreendemo-nos neste estudo com o objetivo de testar uma suposição de que 0 comportamento de usuários de sistemas de informações poderia ser examinado e sua consistência verificada com 0 que se sabe de estudos do comportamento do consumidor.

Todas estas observações sobre o modelo DBN aplicado ao estudo do comportamento do consumidor evidenciam uma similaridade com a hipótese inicial de que, usuários de biblioteca e de sistemas de informações, em geral, podem demonstrar características comportamentais similares àquelas observadas em consumidores de bens materiais. Achados em estudos de pesquisa de mercado podem também ser aplicáveis em tais usuários. Mesmo se questionado que este estudo possa falhar em demonstrar conclusivamente que usuários de sistemas de informação sejam análogos a consumidores e que livros e informações podem ser equiparados com aquisições de bens, a semelhança adicionada aqui mostra que, embora complexos, os modelos matemáticos derivados do DBN podem tornar-se de considerável valor empírico como preditores de comportamento de usuários de biblioteca e/ou de demais provedores de informações.

Os conceitos de novos e reincidentes usos, quando se aplicam a bibliotecas, convida, portanto, à investigação, ambos sobre uma larga escala, para prover uma base empírica ao desenvolvimento de aplicações e futuros refinamentos.

$O$ objetivo deste presente artigo foi demonstrar evidências com base em trabalhos já mencionados na literatura, de que existe uma similaridade entre o comportamento do consumidor de bens e serviços e os usuários de sistemas de informação. Acreditamos que o tempo e o esforço investido será amplamente compensado pelos benefícios práticos a serem derivados da melhoria do conhecimento de como os usuários sistemas de informação se comportam.

As evidências deste estudo parecem ser mais justificativas para aplicação das descobertas da pesquisa de consumidor, com respeito a compradores reincidentes, para os estudos de comportamento de clientes, usuários, ou consumidores em uma faixa maior de ambiente comercial e indústrias de serviços de informação.

Acreditamos que este estudo virá contribuir para a abordagem do conceito de comportamento do usuário de sistemas de informação, por enfocar a informação como um bem de consumo. Imaginamos que servirá como um propósito útil à medida que proporcionar encorajamento para a realização de mais pesquisas dentro de forças motivacionais que são o trabalho para produzir modelos observados de comportamento entre diferentes categorias de consumidor.

Pode-se encarar a aplicação destes estudos para a solução de problemas práticos de gerenciamento e alocação de recursos em bibliotecas, apesar de predições do DBN serem baseadas na pressuposição de um ambiente estável. Pode-se, de fato, prover os ímpetos e a direção necessária para estimular mudanças na maneira que percebemos e fazemos as coisas. A utilidade do modelo pode, portanto caracterizar-se como sendo uma ferramenta mais utilizada em diagnósticos do que para predições, no sentido de que seus benefícios derivam mais do seu valor como um estímulo preferível para agir antecipadamente, do que de visão do futuro. Por exemplo, uma queda antecipada na demanda de um serviço particular ou recurso da biblioteca pode impelir o gerenciamento a investigar os fatores 
ambientais que podem ser contribuição para ele, para rever necessidades dos usuários, e então tomar tais ações praticáveis.

Tomando por exemplo o caso de uma biblioteca acadêmica, o modelo pode indicar um nível mínimo projetado da taxa de uso de um grupo de usuários alvo (por exemplo, estudantes de primeiro ano) ao ponto em que é considerado um baixo nível aceitável. Este pode ser um sinal indicativo para alteração nos procedimentos de gerenciamento da biblioteca, sinalizando que um estudo sobre usuários tem que ser conduzido a fim de identificar problemas relacionados com os serviços disponibilizados pelas bibliotecas com 0 objetivo de modificar e/ou melhor, realocá-los.

Similarmente, o modelo pode ser usado para orientar administradores na resolução dos problemas no uso da biblioteca e demais provedores de informação, no processo de alocação de recursos.

O modelo pode ser usado para assessorar o processo de gerenciamento da biblioteca em determinada carga de trabalho para a instalação de um sistema de controle de circulação automatizado. Geralmente, isto envolve uma sobrecarga considerável na conversão de informações de empréstimos existentes para forma inteligível para máquina.

Com um conhecimento do número de empréstimos individuais dentro de um dado período de tempo, da taxa cumulativa de novos usuários e do ponto no tempo em que é previsto seu declínio, podem ser traçados planos para identificar e alocar os recursos que serão requeridos para permitir o registro de usuários sobre uma base diária de visitantes. Como um resultado, a necessidade para correio de cartas de usuários pode ser eliminada, a identificação de usuários pode ser checada e verificada face a face, e aos novos usuários pode ser realizada uma apresentação sob a forma de uma breve introdução para os serviços e recursos oferecidos pela biblioteca. Todas estas funções dependem da previsão adequada de recursos e o modelo de usuários reincidentes pode ser útil na indicação do grau para o qual devem ser disponibilizados.

Para o futuro, podemos experimentar a aplicação do modelo de compradores reincidentes para a investigação dos padrões de comportamento dos consumidores no caso de mudanças de marca de produtos de consumo, correlacionando e/ou comparando tais padrões com os observados nos usuários reincidentes em bibliotecas, ao investigarmos as reações dos usuários face às formas alternativas de provisão de informação (bibliotecas, utilidades da informação, centros de informação comunitário, serviços de TV a cabo).
No presente ambiente de informação volátil poderemos submeter questões, tais como "qual é o mercado da biblioteca? "e" Como ele é afetado por estes desenvolvimentos". Finalmente, cabe notar que é inevitável que, periodicamente, todo gerente de biblioteca e demais provedores de informação tenham que responder à questão: o que pode ser abandonado para que se possa direcionar alocar recursos para alguma coisa que não esteja sendo feita? [30]

Revisados os conceitos sob o enfoque das pesquisas de consumidor e os associando aos aplicáveis a compradores reincidentes e atitudes comportamentais que levam as pessoas a consumirem bens substitutos, pode-se correlacionar tais situações assumindo novos significados e abrindo novas frentes de investigação, visando obter subsídios para melhorar os sistemas de informação e o atendimento aos seus usuários.

Os trabalhos aqui descritos com as observações inseridas permitiram a visão de uma correlação entre o comportamento do consumidor de bens e o do usuário de informações. Cabe

ressaltar, no entanto a necessidade da criação de um modelo, simples, ao que o modelo DBN apresenta-se um pouco complexo, para avaliação de usos e previsão de demandas de usuários de forma a subsidiar o processo de gestão de recursos informacionais e tecnológicos disponibilizados aos usuários de informação.

\section{Referências Bibliogáficas}

1 SIMONSEN, Mário H. Microeconomia. Rio de Janeiro: F.G.V.,1959. V. 2: Teoria microeconômica.

2 DORNBUSCH, Rudiger, FISCHER, Stanley. Macro-economia. São Paulo: McGraw Hill do Brasil, 1982.

3 SMITH,B.B. Marketing Strategies for Libraries (Bradford: MCB Publications, 1983), 3.

4 SEIBERT, W. F., How Libraries Grow: A Brief Look Backward (and Forwad), Journal of Academic Librarianship 11, 1 ( March 1985)

5 HILL,G. R. Funding, Buying, and Sharing: Natural Sequence, or Unnatural Acts, in collections: Their Developoment, management, Preservation, Conference of national and university Libraries, University of York, September 1988 .

6 BURNS, R. W. Library use as a performance measure: its backroound and rationale, Jornal of academica librrianship 4, 1 ( march 1978).

7 CAHALAN, D. Correlates of respondent accuracy in the Denver Validity survey, "Public opinion quaterly 32 ( winter 1968-69). 
FINE, S. Research and the psychology of information use, library trends 32,4 (spring 1984).

9 CLARCK, P M. New approaches to the measurement of public library use by individual patrons ( Urbana, IL: Graduate school of library and information science, university of Illi9nois, 1983).

10 TWEDT, D. W. Some practical applications of the heavy half Theory in papers presented at the tenth, annual conference, advertising research foundation, New York, October 6, 1964

11 GREENE, J. D.Review of A S C Ehrenberg 's repeat-buying: theory and applications, "journal of marketing research 10 (1973)

12 TRUESWELL, R. W. "Some Behavioral Patterns of Library users: the $80 / 20$ rule, "Wilson Library Bulletin 43 ( 1969).

13 LINE, M. B. "The Half-Life of Periodical Literature: Apparent and Real Obsolescence, "Journal of Documentation. 26 (1970).

14 MCGRATH, W. E. Correlating the subjects of books taken out of and b books used within an open-stack library. College \& Research Libraries. n [S.I.],n.32,1971

15 POOLE, H. L.Theories of the Middle Range (Norwood, N. J.: Ablex Publishing Corporation, 1985).

16 PAISLEY, W. J.The Flow of (Behavioral) Science Information: A Review of the Research Literature (Palo Alto, CA: Stanford University Institute for Communication Research, 1965, II .

17 ZWEIZIG, D. L. Predicting Amount of Library Use: Na Empirical Study of the Role of the Public Library in the Life of the Adult: Public, (PhD diss., Siracuse University, 1973)

18 MORSE, P. M. Library Effectiveness: A Systems Approach (Cambridge, MA:MIT Press, 1968).

19 WARE, J. Dei "A General Statistical Model for estimating Future Demand Levels of DataBase Utilization Within an Information $\mathrm{n}$ Retrieval Organization, "Journal of the American Society of Information Science 24, 4 (July-August 1973)

20 NOZIK, B. S. A stochastic Model to predict demand for library services ( PhD diss., University of California, 1974), 143Nozik, 1974)

21 MERTON, R. K. Social Theory and Social Structure (New York: Free Press, 1968), 39.

22 OLDMAN,C. The Value of Information (Bradford: MCB Publications, 1976)
23 EHRENBERG, A. S. C., Repeat-Buying: Facts, Theory and Applications (New ed. London, New York: Charles Griffin, Oxford University Press, 1988

24 MENZEL, H., "Information Needs and Uses in Science and Tecnology "in Annual Review of Information Science and Technology, 1 (1966).

25 MASSEY,M. E., "Market Analysis and Audience Research for Libraries, "Library Trends 24, 3 January, 1976

26 GREENE, J. D., Consumer behavior models for Non-statisticians: The river of time (New York: Praeger Publishers, 1982)

27 M. G. Kendall and W. R. Buckland, A dictionary of statistical terms ( 2 nd ed.: Edinburgh: Oliver and Boyd, 1960)

28 EHRENBERG, A S C, 'Regularities of Behavior, "in A S C Ehrenberg ( comp.) Consumer Behavior: Selected Readings. (Harmondsworth, Eng.: Penguin Books, 1971)

29 FISHBEINB, M. "Attitude and the Prediction of behavior, "in Fishbeinb, (ed), Readings in attitude Theory and Measurement (New York: Wiley, 1967).

30 MORAN,B. B., academic libraries: the changing knowledge centers of colleges and universities ( [ s. I.] association for the study of higher education, 1984) 30

\author{
Sobre o autor \\ Raquel Dias \\ raquel dias@directnet.com.br \\ raquel dias@yahoo.com \\ Consultora em Tecnologia da Informação \\ Professora de Auditoria de Sistemas e Segurança \\ de Dados (ICAT/DF) \\ Economista, Doutora em Ciência da Informação \\ pela UNB, Mestre em informática pelo ITA. \\ Pós-graduada em: \\ Inteligência Competitiva pela UFRJ/IBICT, \\ Gerência Empresarial (ICAT/DF) \\ Informática (PUC-DF) \\ Análise de Sistemas (PUC-DF) \\ Engenharia Econômica (ICAT/DF)
}

